\title{
Contemporary multimodality imaging evaluation and management of heart valve disease and related conditions
}

Heart valve disease and related conditions, including mitral regurgitation, tricuspid regurgitation and thoracic aortic dilatation, are important conditions affecting many patients worldwide. With advancements in multimodality cardiovascular imaging, including three-dimensional and strain echocardiographic imaging, cardiac computed tomography and cardiac magnetic resonance imaging, there is an improved understanding of the various etiologies of valvular heart disease. In the field of mitral regurgitation and tricuspid regurgitation, these advancements in imaging have been critical in the rapid revolutions in transcatheter mitral and tricuspid valve interventions.

Appropriate imaging evaluation enables the optimal evaluation of patients, provides important risk stratification, and guides optimal management. This dedicated series will provide a contemporary update on left-sided valvular heart disease, mitral valve regurgitation, tricuspid valve regurgitation and thoracic aortic dilatation and aneurysmal disease. In addition, the utility of novel left atrial strain imaging in valvular heart disease and cardiomyopathy and related conditions is covered. Pulmonary hypertension can be associated with many types of valvular heart disease, and an expert Australian group provides a contemporary update on imaging pulmonary hypertension. The role of multimodality imaging extends beyond diagnosis and guiding treatment. This is illustrated in a contemporary review on the role of coronary artery calcium by computed tomography, and related techniques in cardiac risk assessment. Multimodality imaging plays an important role in assessing and guiding many electrophysiology procedures. A unique review article presents a contemporary overview of the roles of multimodality imaging in the field of electrophysiology. With the availability of large volumes of multi-modality imaging data, the field of cardiovascular imaging is at the forefront of a revolution in artificial intelligence and personalized cardiovascular medicine, which is covered by a dedicated review article.

The articles in this special series provide a contemporary update on the diagnosis, evaluation and management of heart valve disease and related conditions, and highlight the roles of multimodality cardiovascular imaging. We believe that these articles are clinically relevant, and hope they will be of interest to the wide readership of Cardiovascular Diagnosis and Therapy.

\section{Acknowledgments}

We would like to thank the editorial team of Cardiovascular Diagnosis and Therapy and Professor Paul Schoenhagen, editorin-chief, for their ongoing dedication to a world-class cardiovascular journal, and for dedicating this special issue to this important topic.

Funding: None.

\section{Footnote}

Provenance and Peer Review: This article was commissioned by the editorial office, Cardiovascular Diagnosis and Therapy for the series "Heart Valve Disease". The article did not undergo external peer review.

Conflicts of Interest: Both authors have completed the ICMJE uniform disclosure form (available at http://dx.doi. org/10.21037/ cdt-21-361). The series "Heart Valve Disease" was commissioned by the editorial office without any funding or sponsorship. Both authors served as the unpaid Guest Editors of the series and report reimbursement by Cleveland Clinic for any scientific meetings and business related travel as appropriate.

Ethical Statement: The authors are accountable for all aspects of the work in ensuring that questions related to the accuracy or integrity of any part of the work are appropriately investigated and resolved.

Open Access Statement: This is an Open Access article distributed in accordance with the Creative Commons Attribution- 
NonCommercial-NoDerivs 4.0 International License (CC BY-NC-ND 4.0), which permits the non-commercial replication and distribution of the article with the strict proviso that no changes or edits are made and the original work is properly cited (including links to both the formal publication through the relevant DOI and the license). See: https://creativecommons.org/licenses/by-nc$\mathrm{nd} / 4.0 \%$.

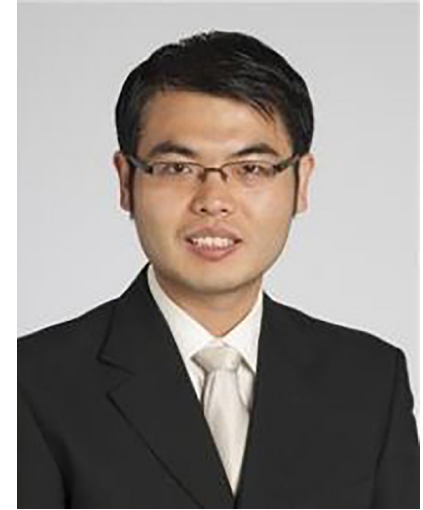

Bo Xu

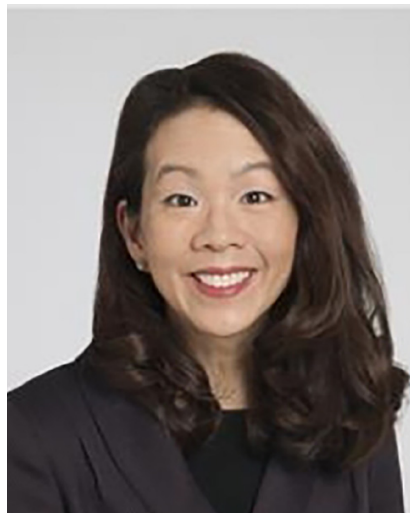

Deborah Kwon
Bo Xu, MD

(Email: xub@ccf.org)

Deborah Kwon, MD

(Email:kwond@ccf.org)

Heart, Vascular, and Thoracic Institute, Cleveland Clinic, Cleveland, OH, USA.

Submitted Jun 08, 2021. Accepted for publication Jun 25, 2021.

doi: $10.21037 / \mathrm{cdt}-21-361$

View this article at: https://dx.doi.org/10.21037/cdt-21-361

Cite this article as: $\mathrm{Xu} \mathrm{B}$, Kwon D. Contemporary multimodality imaging evaluation and management of heart valve disease and related conditions. Cardiovasc Diagn Ther 2021;11(3):768-769. doi: 10.21037/cdt-21-361 